\title{
ANÁLISE AUTOMÁTICA DE OSCILOGRAFIAS EM SISTEMAS ELÉTRICOS DE POTÊNCIA
}

\author{
Miguel Moreto* \\ moreto@labspot.ufsc.br
}

\author{
Jacqueline G. Rolim* \\ jackiedlabspot.ufsc.br
}

*Universidade Federal de Santa Catarina

CEP 88040-900 - Florianópolis SC

Fone: (48) 37219593

\section{RESUMO}

Atualmente os registradores digitais de perturbação estão presentes na maioria das instalações dos sistemas elétricos de potência. Estes equipamentos realizam um monitoramento constante do sistema buscando registrar eventuais distúrbios significativos em grandezas como tensões e correntes. A análise da grande quantidade de dados fornecida por estes equipamentos tem se tornado um desafio para os engenheiros analistas, os quais devem priorizar parte dos registros uma vez que não há tempo hábil para que todos os dados sejam verificados. Desta forma, os registros relativos a ocorrências graves, como desligamentos de geradores ou linhas de transmissão, devem ser analisados em primeira instância. Neste artigo é apresentada uma abrangente revisão bibliográfica relacionada com aplicações de metodologias de análise automática de oscilografias e das técnicas mais utilizadas atualmente. Assim, espera-se que a partir deste artigo o leitor possa adquirir os fundamentos necessários para iniciar o desenvolvimento de esquemas que visem auxiliar os engenheiros especialistas na árdua tarefa de analisar e classificar oscilografias.

PALAVRAS-CHAVE: Registradores digitais de perturbação, oscilografia, sistemas de potência, inteligência computacional.

Artigo submetido em 23/04/2009 (Id.: 00997)

Revisado em 08/06/2009, 03/08/2009, 28/01/2010, 13/04/2010

Aceito sob recomendação do Editor Associado Prof. Antonio Carlos Zambroni de Souza

\section{ABSTRACT}

Automated analysis of digital fault recorder data in power systems

Nowadays the use of digital fault recorders is common practice in most power system substations and plants. These devices continuously monitor signals such as voltages and currents, aiming to record meaningful alterations in their values. The analysis of the huge amount of Digital Fault Recorder data has become a challenge to the specialized engineers, who have to prioritize some records because, in general, there is not enough time to examine all of them. A bibliographic revision concerning applications of automated DFR data analysis methodologies and the most employed computational techniques are presented in this paper. From this article the reader may gain the necessary fundamentals for starting the development of such automated schemes, helping expert engineers in dealing with the classification of the large amount of data provided by DFR.

KEYWORDS: Digital fault recorders, oscillography, power systems, computational intelligence.

\section{INTRODUÇÃO}

Nas usinas e subestações atuais de sistemas elétricos de potência (SEPs) é comum a presença de oscilógrafos para a monitoração de grandezas elétricas como correntes e tensões. Com o avanço da tecnologia digital estes equipamentos tornaram-se menores, mais práticos, mais versáteis e mais baratos do que os antigos oscilógrafos eletromecânicos. Oscilógrafos digitais são também chamados de Registradores 
Digitais de Perturbação (RDPs).

Atualmente os RDPs são uma ferramenta indispensável na análise de ocorrências em um SEP, tanto na geração de energia, quanto na transmissão e distribuição. Existem, inclusive, normas adotadas pelo Operador Nacional do Sistema Elétrico Brasileiro (ONS) estabelecendo que um dos requisitos mínimos necessários em instalações pertencentes ao Sistema Interligado Nacional (SIN) é o RDP (ONS, 2002).

A principal função dos RDPs é de registrar a operação do sistema elétrico e sua proteção durante eventos importantes, como faltas elétricas, oscilações de frequência, falhas operativas, dentre outros. Para isso, os RDPs são ajustados de forma bastante sensível, para garantir o registro do evento mesmo que este não seja suficiente para provocar a atuação dos sistemas de proteção. Desta forma, caso haja atuação indevida da proteção, o registro do RDP poderá ser utilizado para investigar esta atuação e promover medidas corretivas, como o reajuste dos relés de proteção.

Uma das características mais importantes dos RDPs é sua capacidade de ser acessado e configurado remotamente, através de redes de comunicação, geralmente intranets baseadas no protocolo TCP/IP. Assim, podem ser formadas as chamadas redes de oscilografia, conforme será visto mais adiante, onde todas as oscilografias de instalações de uma mesma empresa podem ser concentradas em um único local na rede.

Uma das consequências da popularização dos RDPs são as dificuldades encontradas em armazenar, gerenciar e classificar a grande quantidade de dados que são disponibilizados diariamente em uma rede de oscilografia. Quando se trata de unidades de geração de energia, este problema é agravado devido ao maior número de causas possíveis para o registro de oscilografias nestas instalações em comparação com sistemas de transmissão, por exemplo.

Assim, neste artigo é apresentado um estudo do estado da arte na aplicação de ferramentas computacionais na análise automática de oscilografias, com vistas à redução do tempo gasto pelos engenheiros analistas em seu trabalho bem como no tempo em que determinado componente do sistema permanece fora de operação.

Este artigo é estruturado da seguinte forma: Na próxima seção serão apresentados alguns detalhes do registro de oscilografia em si, bem como suas utilidades em sistemas de energia; na seção 3 são apresentadas algumas metodologias de análise automática de oscilografias que vêm sendo utilizadas em âmbito nacional e mundial, bem como uma descrição das etapas destes procedimentos; nas seções 4 e 5 são expostas, respectivamente, as técnicas de processamento digital de sinais e algoritmos de tomada de decisão mais utilizados em análise de oscilografias. Por fim, na seção 6, são apresenta- das as conclusões do artigo.

\section{OSCILOGRAFIA E APLICAÇÕES}

Oscilografia significa o registro das oscilações de grandezas elétricas do sistema, como tensões e correntes. Em torno da década de 50, a oscilografia era feita por equipamentos eletromecânicos que através de uma agulha móvel registravam as oscilações em um rolo de papel em movimento. A partir dos anos 70, o registro passou a ser feito em papel fotográfico por aparelhos analógicos. Só em meados dos anos 80 surgiram os primeiros oscilógrafos digitais, que foram então chamados de registradores digitais de perturbação (Tcheou, 2005).

Os RDPs são equipamentos de aquisição digital de sinais, desenvolvidos especificamente para serem utilizados em instalações de sistemas elétricos de potência. Sua função principal é gravar continuamente em uma memória cíclica o valor amostrado das grandezas monitoradas. Estas podem ser tensões e correntes de fase ou linha, tensões e correntes de neutro e no caso de geradores, tensão e corrente de campo. A Figura 1 apresenta um diagrama unifilar de uma unidade de geração de energia e as grandezas tipicamente monitoradas pelos RDPs.

Além destas grandezas analógicas, os RDPs também armazenam e monitoram grandezas calculadas, como potências. A mudança de estado de entradas digitais que são ligadas em contatos auxiliares de relés, chaves e disjuntores também é verificada pelo RDP.

O conteúdo da memória cíclica é gravado na memória de registros do RDP cada vez que este for disparado, indicando a ocorrência de uma perturbação. O disparo do oscilógrafo, ou trigger, pode se dar de diversas maneiras, que são programadas na configuração do equipamento. Os métodos mais comuns de trigger são (Martínez et alii, 2008):

- Disparo por limiar: Ocorre se alguma das tensões ou correntes monitoradas atingir certo limiar préprogramado. Este limiar pode ser tanto superior quanto

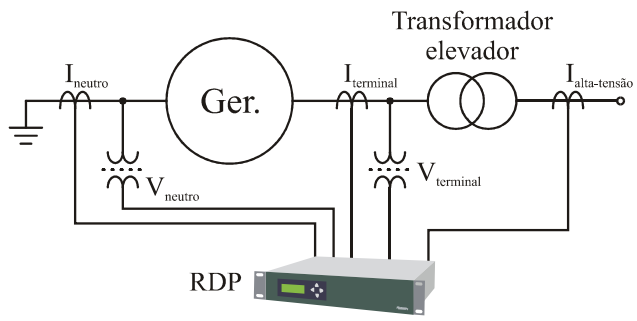

Figura 1: Grandezas típicas monitoradas por um RDP. 
inferior. O disparo por limiar também pode ser utilizado com grandezas calculadas a partir das monitoradas, como potência e frequência.

- Disparo por variação: Ocorre quando a diferença entre os valores eficazes calculados em dois períodos consecutivos excede um limiar pré-configurado.

- Disparo por desequilíbrio: Este tipo de trigger pode ocorrer nos casos em que são medidas grandezas trifásicas. Se estas grandezas apresentarem desequilíbrio entre as fases, haverá o disparo do RDP.

- Disparo sequencial: Válido para os casos em que mais de um RDP está presente em uma mesma instalação. Neste caso, o disparo de um RDP ocasiona o disparo dos demais.

- Disparo por evento digital: O disparo do RDP também pode ocorrer em função da mudança de estado de alguma das entradas digitais. Assim, se as entradas digitais estiverem conectadas a contatos auxiliares de relés de proteção, o RDP pode gerar um registro para cada atuação da proteção.

- Disparo manual: Neste caso, o registro das grandezas monitoradas é feito a partir de um comando manual do operador. Este comando pode ser executado local ou remotamente.

Uma vez que o RDP seja disparado de algum modo mencionado anteriormente, é gerado um registro de ocorrência contendo os valores medidos em um intervalo de tempo pré e pós-disparo. Em cada registro, todos os canais monitorados pelo RDP são armazenados. As três formas mais comuns de registro das grandezas medidas são as seguintes:

- Curta duração: Os registros de curta duração, também chamados de registros de forma de onda, apresentam um tempo de registro da ordem de segundos (em geral, até 20 segundos). Neste registro os sinais de corrente e tensão são amostrados a uma taxa de aquisição programável elevada, em média de 720 a 11520 amostras por segundo. Um exemplo deste tipo de registro pode ser visto na Figura 2.

- Fasoriais: Os registros fasoriais são aqueles que apresentam um tempo de registro da ordem de minutos e armazenam informações de módulo e ângulo da corrente e tensão adquiridas em uma taxa programável que em geral é de uma amostra por ciclo de freqüência fundamental. Um exemplo pode ser visto na Figura 3, a qual apresenta um registro cuja duração é 6 minutos. Estas informações permitem a realização de análises e o cálculo de fluxos de potência, sendo muito importantes para a análise de estabilidade do sistema de potência e para a visualização de oscilações de baixa freqüência;

- Medição contínua: Um registro de medição contínua é composto dos valores médios de módulo e ângulo calculados em intervalos maiores, em geral, de 1 minuto, a partir dos sinais fasoriais de corrente e tensão medidos. Esses dados são armazenados em uma memória circular que contém as informações sobre os últimos dias.

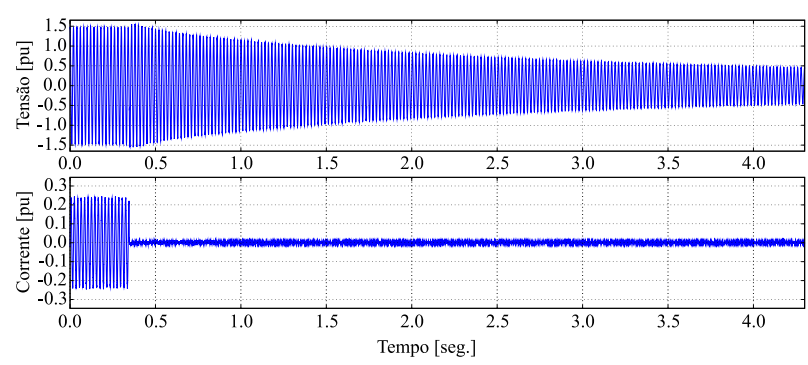

Figura 2: Exemplo de registro de forma de onda.

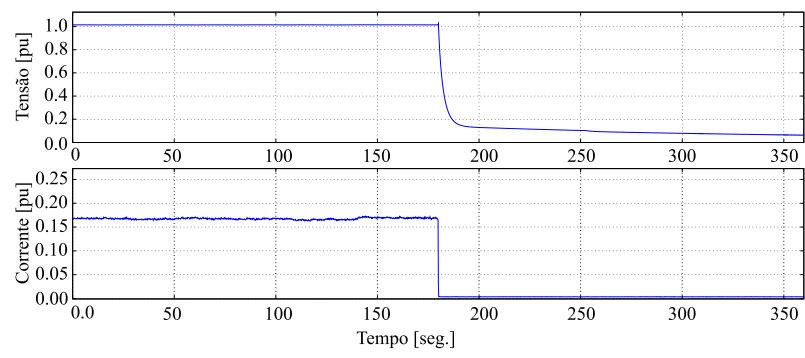

Figura 3: Exemplo de registro fasorial, neste caso, o gráfico apresenta apenas o módulo dos fasores ao longo do tempo.

Conforme já mencionado, os RDPs podem ser acessados e configurados remotamente através de redes de computadores formando as chamadas redes de oscilografia. Nestas redes, todos os registros de oscilografia provenientes de diversos oscilógrafos são armazenados em um único servidor, localizados geralmente na sede da empresa. Os analistas então podem acessar remotamente este servidor e verificar as oscilografias (ver Figura 4).

Nesta configuração os analistas podem não ser capazes de verificar todas as oscilografias que diariamente são disponibilizadas no servidor em função da grande quantidade de registros. Isto ocorre devido a diversos motivos, dentre os quais podem-se citar:

- O ajuste sensível dos triggers dos RDPs, escolhidos para garantir que o equipamento não deixe de registrar alguma ocorrência importante. 


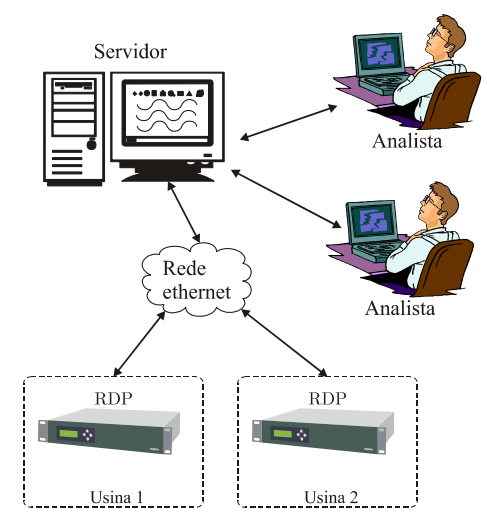

Figura 4: Exemplo de rede de oscilografia.

- A frequente atuação dos RDPs devido a eventos digitais, por vezes desnecessárias, como no caso de testes dos sistemas de proteção ou durante procedimentos de manutenção.

- A grande quantidade de RDPs e de sinais monitorados nas subestações e usinas.

Conforme será visto mais adiante, no servidor de oscilografias podem ser aplicadas metodologias de análise automática de oscilografias cuja funcionalidade se assemelha a um filtro classificador de ocorrências (Silva et alii, 2006). Com isso o analista pode se concentrar nos registros de ocorrências mais graves enquanto os casos irrelevantes nem sequer precisam ser analisados por uma pessoa.

Os registros de oscilografia têm se mostrado extremamente úteis para diversas aplicações em sistemas elétricos de potência, especialmente devido às funcionalidades adicionais dos RDPs em relação aos antigos registradores analógicos (Zimath et alii, 2005). Dentre estas funcionalidades dos RDPs, destacam-se os registros fasoriais de longa duração, o registro de estados digitais, comunicação remota e sincronismo temporal dos registros através do sistema de posicionamento global (GPS).

Nas subseções a seguir, serão apresentadas algumas aplicações em que a oscilografia vem sendo utilizada com sucesso.

\subsection{Análise de ocorrências}

A análise de ocorrências pode ser considerada a aplicação mais comum da oscilografia em sistemas de energia. Nesta aplicação a oscilografia é utilizada para verificar a causa de perturbações no sistema elétrico, como perdas de linhas de transmissão, desligamentos de geradores, manobras na rede básica, etc.
As perturbações geram distúrbios no sistema elétrico que podem provocar atuações de proteções e/ou disparo de RDPs. Verificando um ou mais registros de oscilografia os analistas podem identificar em qual componente do sistema elétrico a perturbação teve origem e até mesmo sua causa.

Em análise de ocorrências em geradores, os registros de forma de onda, com duração de alguns segundos, podem não ser suficientes para registrar algumas ocorrências nestes equipamentos. Devido à elevada inércia destas máquinas, os transitórios associados tendem a ser mais lentos do que linhas de transmissão. Problemas no sistema de excitação, por exemplo, podem não ser completamente cobertos por um registro de forma de onda. Assim, os registros fasoriais, com duração de alguns minutos, são amplamente utilizados em usinas (Zimath et alii, 2005).

Com a oscilografia é possível verificar, por exemplo, se a causa do desligamento de um gerador foi devido à falha de algum equipamento, um curto-circuito ou uma causa externa.

A análise de ocorrências no sistema elétrico é extremamente importante para se determinar quais os componentes do sistema que ocasionaram o distúrbio e com isso orientar as ações corretivas necessárias e responsabilizar os agentes envolvidos em casos de negligência.

\subsection{Localização de faltas em linhas de transmissão}

Uma das utilizações mais conhecidas e antigas para os registros de oscilografia é a localização de faltas, que consiste na determinação da distância do ponto de ocorrência de uma falta (curto-circuito) em relação a um dos terminais de uma determinada linha de transmissão. Assim, as equipes de manutenção podem ser despachadas diretamente ao local provável da ocorrência.

Existem muitos trabalhos publicados propondo diversos algoritmos de localização de faltas. A maioria deles pode ser utilizada com dados de registros de oscilografia, seja de curta ou longa duração.

Para a localização de faltas, podem ser utilizados registros provenientes de apenas uma ou de ambas as extremidades da linha de transmissão, conforme apresenta a proposta de Girgis e Fallon (1992).

Com a possibilidade de amostragem sincronizada por GPS o uso dos RDPs na localização de faltas pode ser aprimorado, utilizando os registros sincronizados de ambos os lados da linha de transmissão (Kezunovic e Perunicic, 1995).

Atualmente, novas funções incorporadas aos registradores de perturbação, como a medição fasorial sincronizada, permi- 
tem que os dados fasoriais obtidos dos RDPs possam ser utilizados diretamente para a localização de faltas em linhas de múltiplos terminais (Liu et alii, 2008).

A utilização dos RDPs na localização de faltas é também proposta para sistemas de distribuição, os quais são essencialmente radiais (Bretas et alii, 2006; Vale et alii, 2006).

\subsection{Análise do desempenho da proteção}

Outra aplicação bastante comum das oscilografias é a avaliação do desempenho do sistema de proteção durante condições de operação crítica do sistema. Nesta aplicação, buscase verificar as seguintes condições (Zin e Karim, 2007):

- A atuação dos dispositivos de proteção foi correta.

- Algum dos dispositivos de proteção operou quando não deveria atuar.

- A proteção principal não operou quando deveria atuar (a falta não foi eliminada, ou foi eliminada por outros dispositivos de proteção).

- O tempo de atuação da proteção não foi o esperado.

Existem diversas abordagens utilizadas nestas aplicações. Uma das mais conhecidas consiste na modelagem dos dispositivos de proteção. Uma vez tendo o modelo definido, o registro de oscilografia é aplicado neste modelo, comparandose a resposta obtida do modelo (considerada como correta) com a resposta real obtida através do registro das grandezas digitais no RDP ou até mesmo de sistemas supervisórios. Exemplos desta aplicação baseada em modelos podem ser vistos em Davidson et alii (2003) e em Luo e Kezunovic (2005a).

\subsection{Análise de equipamentos}

Os registros de oscilografia também podem ser utilizados para a avaliação do estado de equipamentos em sistemas elétricos de potência.

O objetivo desta análise é principalmente identificar possíveis falhas incipientes em equipamentos como transformadores, transformadores de potencial capacitivo (TPCs) e disjuntores. Desta forma, a oscilografia é utilizada como ferramenta para orientação da manutenção destes equipamentos antes que os mesmos apresentem uma falha mais grave que em casos extremos poderia resultar em interrupção no fornecimento de energia.

No trabalho de Futino et alii (2009), os registros de oscilografia de curta duração são utilizados para avaliar possíveis defeitos de TPCs a partir do monitoramento da tensão secundária de sequência zero. A Figura 5 apresenta uma oscilografia utilizada nesta aplicação, juntamente com a tensão de sequência zero calculada a partir do registro de curta duração.

A metodologia proposta visa determinar possíveis defeitos nas colunas capacitivas ou no transformador indutivo dos TPCs.

A atuação de disjuntores também pode ser avaliada com o intermédio das oscilografias. A análise dos transitórios nos sinais de corrente no momento da abertura do disjuntor pode fornecer indícios de degradação do seu desempenho (Silva et alii, 2004).
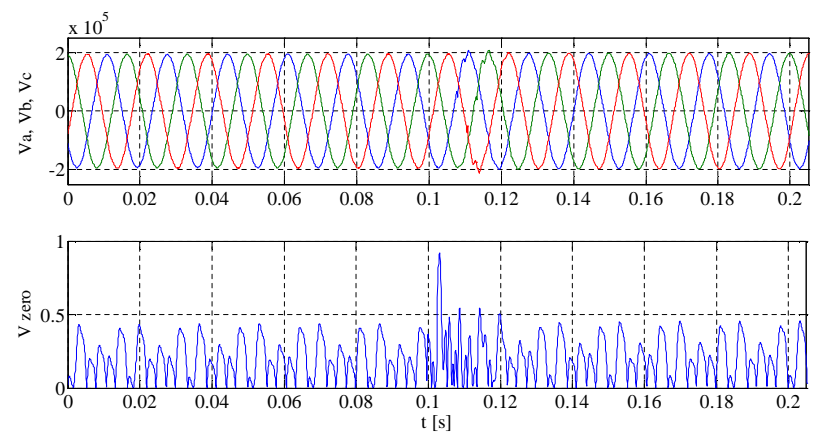

Figura 5: Exemplo de uso da oscilografia para avaliação de TPCs através do calculo da componente se sequência zero.

\subsection{Análise de qualidade de energia}

Os registros de oscilografia podem ser utilizados também para verificar se os índices de qualidade de energia de um determinado agente do setor elétrico apresentam valores aceitáveis. Neste sentido, buscam-se identificar, através dos dados dos RDPs, casos como (Melo, 2008):

- Variações de tensão.

- Cortes e afundamentos momentâneos de tensão.

- Surtos de tensão.

- Variações de freqüência.

- Desequilíbrio de tensão.

- Cintilação.

- Distorção harmônica.

Na maioria dos casos, são utilizados registros de curta duração para identificação destes distúrbios. Algumas destas aplicações podem, ser vistas no trabalhos de Styvaktakis et 
alii (2002a) e a nível nacional em Ferreira et alii (2009). Os registros de longa duração também podem ser utilizados, através do módulo do registro fasorial que normalmente corresponde ao valor eficaz da grandeza $(\mathrm{rms})$. Com este tipo de registro, podem-se identificar eventos relacionados à qualidade de energia como, energizações, interrupções no fornecimento, saturação de transformadores, partida de motores de indução, mudanças abruptas e faltas (Styvaktakis et alii, 2002b).

\section{SISTEMAS DE ANÁLISE AUTOMÁTICA DE OSCILOGRAFIAS}

Como pôde ser visto nas seções anteriores, a oscilografia é uma ferramenta bastante versátil e útil na análise de ocorrências em sistemas de potência. Porém, esta análise requer conhecimento especializado do sistema e sua proteção, além de envolver o manuseio de grande quantidade de informações como oscilografias de outros pontos do sistema e informações de outros sistemas de monitoramento (Kezunovic et alli, 2001).

Nota-se que o procedimento de análise de ocorrências usando registros oscilográficos é uma tarefa que demanda um tempo considerável e deve ser executada por profissionais treinados. Os fatores que aumentam o tempo necessário para um especialista realizar uma análise são, em geral, os seguintes:

- Atrasos na transmissão dos dados dos RDPs das instalações até a central de análises devido à baixa capacidade e qualidade dos sistemas de comunicação, ocasionando demoras no processo de busca dos registros de oscilografia. Os dados envolvidos podem ser oriundos de instalações diferentes. O especialista deve então escolher quais fontes de dados vai utilizar na análise e realizar a cópia dos arquivos para a estação de análise.

- Quantidade de registros a serem verificados. Em uma mesma instalação podem existir diversos RDPs, os quais normalmente estão interconectados de tal modo que o disparo de um deles ocasiona o disparo dos demais. Desta forma o especialista deve verificar todos os arquivos em busca de possíveis efeitos secundários da perturbação original.

- Correlação dos dados de oscilografia com outros sistemas. Geralmente os dados de oscilografia não são analisados individualmente, fazendo-se necessário sua correlação com dados de outros sistemas, como os supervisórios, manutenção e faturamento.

- Verificação dos procedimentos. Durante a análise, o especialista precisa conhecer os procedimentos adotados na instalação, como procedimentos de parada e partida de máquinas, filosofias de proteção e limites de operação normal. Em uma empresa com diversas instalações diferentes, como usinas e subestações, um tempo considerável é gasto com estas verificações durante o processo de análise.

A complexidade e quantidade dos dados verificados durante o processo de análise de uma ocorrência são os principais motivadores para o desenvolvimento de sistemas computacionais de análise automática. A seguir serão apresentados brevemente alguns trabalhos publicados com propostas e desenvolvimentos de sistemas deste tipo.

No trabalho descrito em (Hossack et alii, 2002) e (McArthur et alii, 2004) foi desenvolvido um sistema multiagente onde as diversas etapas de análise são realizadas por módulos (ou agentes) separados, mas que se comunicam (ver Figura 6). Neste sistema, um dos agentes identifica primeiramente, através dos dados do sistema supervisório, se houve uma ocorrência e sua localização sistema, como, por exemplo, em qual subestação ou usina ocorreu. Esta informação é disponibilizada aos demais agentes responsáveis por coletar as oscilografias necessárias, processar as informações nestes registros, diagnosticar a causa do registro, avaliar a atuação do sistema de proteção e disponibilizar os resultados aos usuários.

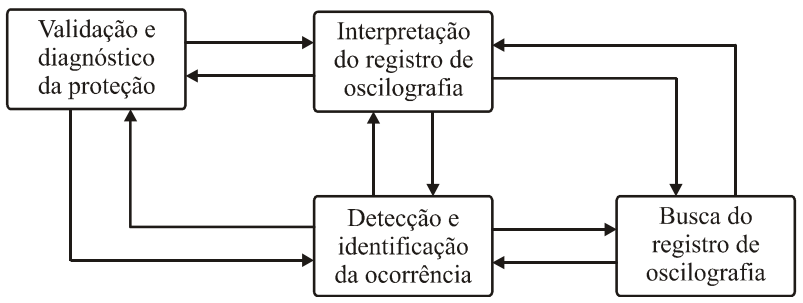

Figura 6: Agentes inteligentes para análise de ocorrências (Hossack et alii, 2002).

No trabalho de Davidson et alii (2006) é apresentada uma nova versão do sistema multiagente, desenvolvida de acordo com padrões internacionais estabelecidos pela Foundation for Intelligent Physical Agents (FIPA), com o acréscimo de alguns agentes e resultados da aplicação do esquema em partes do sistema elétrico do Reino Unido.

Em âmbito nacional, um trabalho foi desenvolvido pela Universidade Federal de Campina Grande para a CHESF. Neste trabalho foi implementada uma metodologia de análise automática de oscilografias utilizada para detectar e classificar faltas no sistema de transmissão da CHESF. O método é baseado em processamento digital de sinais por transformada wavelet e um classificador baseado em redes neurais artificiais (Silva et alii, 2006; Silva et alii, 2007). Para validação da metodologia foram utilizados dados de simulação, bem 
como dados reais do sistema elétrico.

Também no âmbito nacional, esforços vêm sendo feitos pelo operador nacional do sistema elétrico (ONS) para desenvolver um sistema integrado de análise de perturbações (SPERT) capaz de coletar e analisar oscilografias. Uma visão geral deste trabalho pode ser vista em Giovanini et alii. (2008). Trata-se de um sistema completo de gerenciamento e visualização de oscilografias. Um dos módulos deste sistema realiza uma filtragem das oscilografias, de modo a priorizar quais registros devem ser analisados pelas equipes do ONS. O objetivo é buscar apenas as oscilografias diretamente relacionadas com a perturbação, ignorando os demais RDPs disparados devido à detecção de uma ocorrência externa. Além disto, os registros selecionados podem ser pré-analisados automaticamente.

Nota-se que todos os trabalhos citados até o momento foram desenvolvidos especificamente para serem aplicados em sistemas de transmissão de energia. São poucos os trabalhos aplicados em outros setores do sistema elétrico, como nos sistemas de geração. Todas as usinas de grande porte do sistema interligado nacional devem possuir pelo menos um RDP (ONS, 2002). Assim, sistemas de análise automática de oscilografias também podem ser utilizados para geração. Uma aplicação deste tipo vem sendo estudada e desenvolvida pelos autores deste artigo e os resultados obtidos até o momento demonstram a importância de um sistema automático de análise de oscilografias, tanto na melhoria da qualidade quanto na redução do tempo despendido em cada análise (Moreto e Rolim, 2008).

Nos trabalhos descritos na literatura, verifica-se que a principal finalidade dos sistemas de análise automática de oscilografias é realizar tarefas repetitivas que normalmente seriam feitas pelo engenheiro analista. Além disso, com a utilização de técnicas de processamento digital de sinais e algoritmos de inteligência artificial estes sistemas podem ser dotados de capacidade de identificar e classificar automaticamente as ocorrências mais comuns em sistemas de energia elétrica.

Estes sistemas consistem em ferramentas de auxílio, provendo meios para que o engenheiro especialista analise apenas as ocorrências de maior significância, como, por exemplo, desligamentos forçados e faltas. De fato, no caso de sistemas de geração, estes casos representam um percentual baixo (em torno de 2 a 5\%) do total de registros gerados pelos RDPs (Varela et alii, 2009). Assim, em torno de 95\% dos registros de oscilografia podem ser processados automaticamente pelos sistemas em questão.

A maioria das metodologias de análise automática de oscilografias, seja qual for o problema abordado, diagnóstico de faltas, qualidade de energia, desempenho da proteção, etc., podem ser divididas nas etapas apresentadas na Figura 7.
A primeira etapa a ser realizada é a obtenção do registro de oscilografia, que pode ser feita manualmente ou automaticamente, caso exista um sistema integrado de coleta e gerenciamento destes arquivos. Estes sistemas automatizados variam conforme o fabricante dos RDPs e as necessidades da empresa. Em alguns casos (Hossack et alii, 2002; Davidson et alii, 2006) esta tarefa é realizada por um agente inteligente dedicado.

As demais etapas presentes na Figura 7 serão descritas nas subseções a seguir.

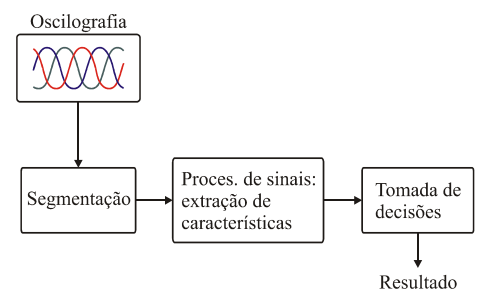

Figura 7: Principais etapas de um sistema de análise automática de oscilografias.

\subsection{Segmentação}

Após a obtenção do registro de oscilografia, deve-se definir como os dados serão utilizados, ou seja, se todo o registro será processado de uma vez ou se a análise será feita em partes, através da segmentação do sinal. Esta escolha vai depender do tipo de distúrbio que se deseja analisar. Bollen e $\mathrm{Gu}$ (2006) definem basicamente dois tipos de distúrbios:

- Variações: São distúrbios em regime permanente, ou quase regime permanente, como, por exemplo, a existência de conteúdo harmônico indesejável na rede elétrica.

- Eventos: São distúrbios bruscos, como interrupções, afundamentos de tensão, faltas, entre outros.

Apesar de serem definidos para estudos de qualidade de energia, estes termos também podem ser utilizados em outras aplicações.

É na etapa de segmentação que os eventos (ou variações) são detectados e, caso necessário, o registro da oscilografia é dividido em partes conforme a necessidade da metodologia de análise utilizada. Um exemplo é a segmentação do registro de oscilografia contendo um curto-circuito em intervalos préfalta, falta e pós-falta, conforme a Figura 8, onde um registro de longa duração foi segmentado nestas três partes. Neste registro é armazenado um fasor (módulo e fase) para cada ciclo da frequência fundamental do sistema. O segmento de falta é representado pela região hachurada. 


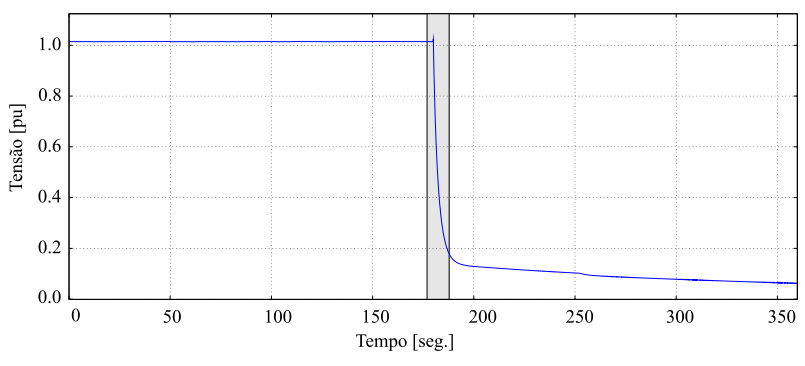

Figura 8: Exemplo de segmentação de um sinal proveniente de um registro de longa duração.

Para realizar a segmentação, normalmente são definidos limiares máximos de variação de grandezas de interesse como o valor eficaz calculado, o módulo da componente de frequência fundamental ou de uma determinada harmônica ou a potência. Para este fim, também podem ser empregadas ferramentas de processamento digital de sinais como a Transformada de Fourier ou Wavelet que são as mais utilizadas e serão apresentadas em maiores detalhes na Seção 4.

\subsection{Extração de características}

Feita a segmentação, a próxima etapa é a extração de características em cada segmento. A escolha das características vai depender do problema abordado e da metodologia de solução. Na bibliografia pesquisada, as características mais utilizadas são:

- Valores médios ou eficazes das grandezas monitoradas (tensões e correntes) em cada segmento (Styvaktakis et alii, 2002b; Moreto e Rolim, 2008);

- Valores médios de grandezas calculadas como potência elétrica ou componentes simétricas (Kezunovic, 2000);

- Conteúdo harmônico dos dados, obtido através da transformada de Fourier (Bretas et alii, 2006);

- Coeficientes de detalhe obtidos com a análise multirresolução da transformada wavelet (Youssef, 2001).

A extração de características tem a função de reduzir a quantidade de dados a serem utilizadas para avaliar, automaticamente ou não, a ocorrência registrada pelo RDP.

\subsection{Tomada de decisão}

Esta etapa, que é a última apresentada na Figura 7, consiste em analisar efetivamente os dados resultantes da etapa de extração de características para se obter uma conclusão a respeito da ocorrência.
Nas metodologias de análise automática de oscilografias geralmente são empregadas técnicas de Inteligência Artificial, as quais foram desenvolvidas com o intuito de emular o comportamento de um ser humano realizando a tarefa. Conforme será visto na seção 5, as técnicas mais utilizadas são sistemas especialistas e redes neurais artificiais.

\section{TÉCNICAS DE PROCESSAMENTO DE SINAIS}

Conforme mencionado anteriormente, nas etapas de segmentação e extração de características freqüentemente são empregadas técnicas de processamento digital de sinais. Nesta seção, estas técnicas serão apresentadas brevemente, bem como suas principais vantagens e como são mais utilizadas.

\subsection{Mínimos Quadrados}

O método dos mínimos quadrados consiste em ajustar um conjunto de pontos, ou medidas, a uma função conhecida, como uma reta, exponencial, polinômio, etc. Trata-se de um problema de minimização onde busca-se reduzir a soma dos quadrados das diferenças entre a curva ajustada e os dados medidos. Ou seja:

$$
\min \sum_{i=1}^{N}\left(y_{i}-f\left(x_{i}\right)\right)^{2}
$$

Onde $\left(x_{i}, y_{i}\right)$ são as coordenadas dos pontos medidos e $f($. é a função para a qual se deseja ajustar a curva.

Este método é utilizado em sistemas de potência para estimar parâmetros como módulo e fase da componente fundamental, bem como de harmônicas (Sachdev e Baribeau, 1979; Phadke e Thorp, 1988).

Na sua forma mais simples, um sinal senoidal $f(t)$ em um dado instante de tempo $t_{1}$ é modelado conforme (2).

$$
f\left(t_{1}\right)=X_{1} \operatorname{sen}\left(\omega_{0} t_{1}+\theta_{1}\right)
$$

Expandindo o termo seno, pode se re-escrever (2) de outra maneira, resultando em (3).

$$
f\left(t_{1}\right)=a_{11} x_{1}+a_{12} x_{2}
$$

Onde:

$$
\begin{aligned}
& x_{1}=X_{1} \cos \left(\theta_{1}\right) ; x_{2}=X_{1} \operatorname{sen}\left(\theta_{1}\right) \\
& a_{11}=\operatorname{sen}\left(\omega_{0} t_{1}\right) ; a_{12}=\cos \left(\omega_{0} t_{1}\right)
\end{aligned}
$$


Considerando que o sinal $f(t)$ é amostrado em intervalos de $\Delta t$ segundos, pode-se escrever um sistema de equações da forma de (3) onde os valores de $f\left(t_{1}\right), f\left(t_{2}\right), \ldots, f\left(t_{N}\right)$ etc. são os valores medidos em uma janela de $N$ amostras e as variáveis $x_{1}$ e $x_{2}$ são as incógnitas (estados). Este sistema pode ser escrito na forma matricial conforme (5).

$$
[A][x]=[b]
$$

Onde $b$ são as medidas.

Para que as variáveis possam ser estimadas, é necessário que o número de amostras seja maior que o de variáveis. Assim, a matriz $A$ do sistema de equações (5) é retangular e não possui inversa.

A solução do problema de mínimos quadrados para este modelo de sinal é obtida através de (6), utilizando a matriz pseudo-inversa (Phadke e Thorp, 1988).

$$
[\hat{x}]=\left[[A]^{T}[A]\right]^{-1}[A]^{T} \cdot[b]
$$

Os elementos do vetor $\hat{x}$ são as estimativas das variáveis de estado. A partir de seus valores, pode-se calcular o fasor de frequência fundamental estimado para uma janela de $k$ amostras. Assim, a cada nova amostra, pode-se calcular novamente o fasor e com isso obter um perfil da componente fundamental (ou harmônicas) do sinal. A partir deste perfil, pode-se segmentar os dados e extrair características, como médias de segmentos pré-falta e pós-falta para dar subsídio aos algoritmos de tomada de decisão (Sachdev e Baribeau, 1979). A Figura 9 apresenta um exemplo do módulo da componente fundamental obtida de um registro de curta duração utilizando uma janela com 115 amostras, correspondendo a um ciclo da frequência fundamental de $60 \mathrm{~Hz}$. A janela de cálculo é deslocada a cada amostra do sinal.
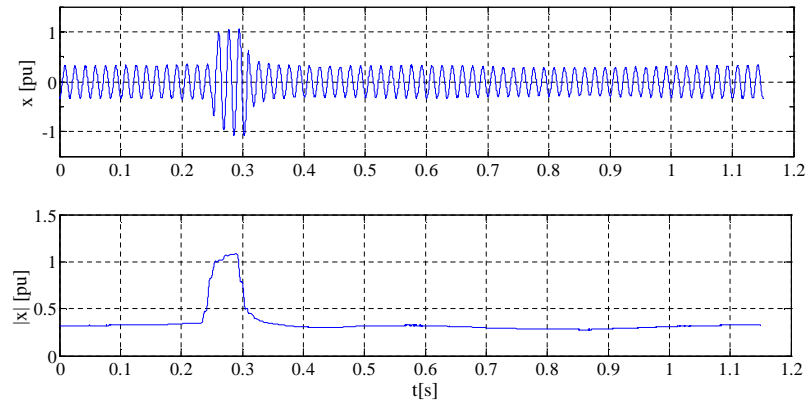

Figura 9: Estimação do módulo da componente de frequência fundamental usando o método dos mínimos quadrados.

\subsection{Transformada de Fourier}

A Transformada de Fourier (TF) é uma das técnicas mais conhecidas para análise de sinais. Ela consiste em uma operação linear de transformação de um sinal no domínio do tempo $x(t)$ para um sinal no domínio da frequiência $X(\omega)$. Originalmente a TF foi definida para sinais contínuos, mas também pode ser definida para sinais digitais, como é o caso dos dados de oscilografia. A Transformada de Fourier Discreta (DFT) é dada pela equação a seguir (Phillips e Parr, 1995):

$$
X[k]=\sum_{n=0}^{N-1} x[n] e^{-j \frac{2 \pi k n}{N}}
$$

Onde $k$ é o índice do vetor de freqüências, $x[n]$ é o sinal amostrado a cada $T$ segundos com $N$ amostras:

$$
x[n]=x(n T) n=0,1,2, \ldots, N-1
$$

Como a maioria dos transitórios não é constante, varia ao longo do tempo, a transformada de Fourier pode não os representar corretamente. Assim, em aplicações práticas, ao invés de se utilizar toda a duração do sinal, é comum calcular a DFT em partes menores deste, de modo que nestas "janelas" o transitório possa ser considerado estacionário. Este método consiste em utilizar uma janela móvel que realiza uma varredura em todo o sinal. A cada deslocamento da janela a DFT é calculada. Dá-se o nome de transformada de fourier digital com janelamento a este procedimento. Na literatura é comumente utilizado o termo em inglês Short Time Fourier Transform (STFT) (Robertson et alii, 1996; Oleskovicz et alii, 2006). Este método assume que o sinal sob análise é periódico localmente em uma janela de tempo constituída de $M$ amostras $(M<N)$, que é deslocada ao longo do sinal. A STFT é definida a seguir:

$$
\operatorname{STFT}[k, m]=\sum_{n=0}^{N-1} x[n] \omega[n-m] e^{-j \frac{2 \pi k n}{M}}
$$

Nesta definição verifica-se que a STFT é igual a DFT, porém o sinal $x[n]$ é multiplicado por uma sequiência de pontos $\omega[n-m]$ que constitui a janela de tempo deslocada de $m$ amostras. Esta seqüência, na forma mais simples é a janela retangular dada em (9). No entanto, outras formas de janelas podem ser utilizadas como apresentado em Oleskovicz et alii (2006).

$$
\omega[n-m]=\left\{\begin{array}{cc}
1 & \text { se } 0 \leq n-m \leq N-1 \\
0 & \text { demais casos }
\end{array}\right.
$$


Em (9), $0<m<M$ e $M$ é o número de amostras que compõem a janela.

A STFT produz para cada deslocamento $m$ da janela uma sequiência de valores representando as componentes de frequiência do sinal de entrada $x[n]$. Assim, o resultado da STFT pode ser visualizado como um gráfico tridimensional onde as divisões horizontais representam as posições das janelas no tempo e as divisões verticais representam as freqüências $k$. Um exemplo obtido de Robertson et alii (1996) é apresentado na Figura 10, mostrando o sinal de entrada com transitório e na Figura 11 o resultado da STFT para uma janela com o tamanho de um ciclo da frequência fundamental. O tom de preenchimento de cada retângulo formado representa a magnitude da transformada.

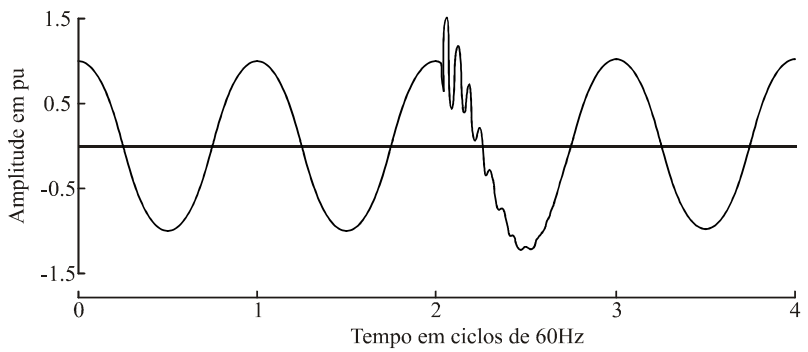

Figura 10: Sinal distorcido devido a um transitório na rede elétrica (Robertson et alii, 1996).

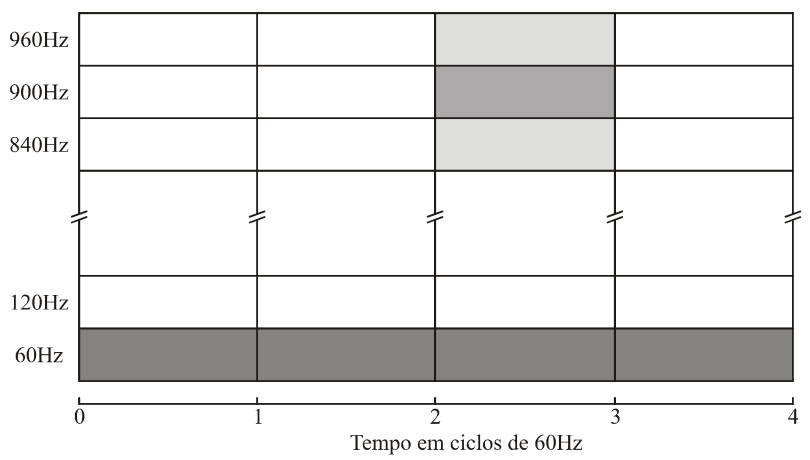

Figura 11: Resultado da análise através da STFT (Robertso et alii, 1996).

Nota-se que a STFT passa a apresentar uma dimensão d tempo, podendo ser utilizada para detectar e determinar । instante de ocorrência das perturbações.

O tamanho da janela $M$ (sua duração no tempo) possui uma relação direta com a resolução do eixo de freqüências. Uma janela com tamanho menor aumenta a resolução temporal, possibilitando maior precisão na identificação do instante de ocorrência, porém, diminui a resolução de freqüências dificultando a caracterização do distúrbio (Xu et alii, 2006). As relações entre o tamanho da janela e as resoluções de frequência e tempo podem ser vistas em (10).

$$
\Delta f=\frac{f_{s}}{M} ; \quad \Delta t=M \cdot \frac{1}{f s}
$$

Vale observar que na figura apresentada não há superposição quando a janela é deslocada.

\subsection{Transformada Wavelet}

Para suprir as deficiências da STFT no que diz respeito à relação entre resolução de frequência e tempo pode ser utilizada uma analise multiresolução. A ferramenta mais utilizada neste caso é a Transformada Wavelet (TW). A TW é uma técnica de análise que avalia um dado sinal nos domínios tempo e frequência simultaneamente.

A transformada wavelet contínua (TWC) é dada em (11), a qual mostra como a função $f(t)$ é decomposta por um conjunto de funções $\psi_{a, b}(t)$ chamadas de wavelets. As wavelets possuem o mesmo papel que as funções seno e cosseno na transformada de Fourier. No entanto, na TW elas são versões escalonadas e transladadas de uma mesma função base, chamada wavelet mãe, cuja expressão geral pode ser vista em (12). Um exemplo de wavelet mãe pode ser visto na Figura 12.

$$
\begin{gathered}
W(a, b)=\int f(t) \psi_{a, b}(t) d t \\
\psi_{a, b}(t)=\frac{1}{\sqrt{a}} \psi\left(\frac{t-b}{a}\right)
\end{gathered}
$$

As variáveis $a$ e $b$ são os fatores de escalonamento e translação.

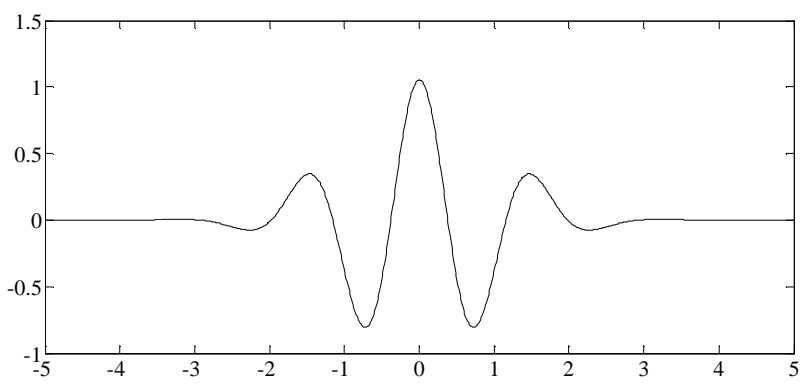

Figura 12: Exemplo de função wavelet mãe.

Se para uma determinada escala e instante a wavelet possui uma correlação significativa com o sinal $f(t)$, então um valor elevado da transformada é obtido. A TW é obtida calculando esta correlação para vários instantes (deslocamentos) e para 
várias escalas. Isto pode ser feito de uma maneira contínua (TWC) ou em passos discretos (Transformada Wavelet Discreta). A TW permite então que o sinal seja analisado nos domínios escala e tempo, possibilitando a identificação dos instantes de ocorrência dos transitórios.

Uma das propriedades das funções wavelets é a condição de admissibilidade, a qual implica que não há componentes de frequência zero no espectro de frequências da função wavelet. Ou seja seu valor médio deve ser nulo. Desta forma, a convolução do sinal com as wavelets pode ser visto como um processo de filtragem utilizando filtros passa banda, cujas larguras de banda dependem do fator de escalonamento. Assim, wavelets comprimidas no tempo $(a<1)$ apresentam bandas de frequência expandidas e deslocadas (já que não possuem componentes de frequência zero) e o inverso para os casos em que $a>1$, conforme ilustrado na Figura 13 .

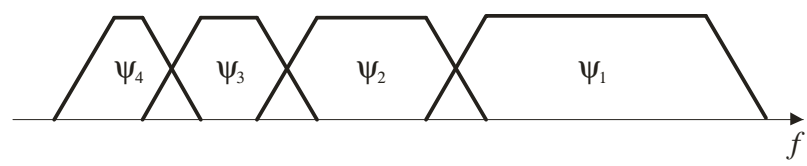

Figura 13: Espectro de frequências resultante do escalonamento da função wavelet mãe.

A condição de admissibilidade implica que um número infinito de funções wavelets é necessário para representar um sinal com valor médio (ou componente de frequência zero) diferente de zero. Além disso, a TWC é altamente redundante e na maioria dos casos a função wavelet não tem solução analítica. Tais fatores dificultam a implementação computacional da TWC (Valens, 1999). Assim, em aplicações práticas é utilizada e Transformada Wavelet Discreta (TWD).

Na TWD a expansão segue um determinado padrão em passos discretos na escolha dos parâmetros $a$ e $b$. Com a escolha adequada destes parâmetros, resolve-se o problema da redundância da TWC. A TWD é dada em (13) (Robertson et alii, 1996).

$$
T W D[j, k]=\frac{1}{\sqrt{a_{0}^{j}}} \sum_{n=0}^{N-1} x[n] g\left[\frac{n-k a_{0}^{j}}{a_{0}^{j}}\right]
$$

Por possuir o parâmetro de deslocamento no tempo, a análise wavelet atua como um janelamento análogo à STFT, porém a resolução em frequiência é dada pelo parâmetro de escalonamento $a$. Assim, o fator de escalonamento está associado com a banda de frequiência e o fator de deslocamento com o tempo. Controlando estes fatores pode-se obter uma análise com diferentes relações entre as resoluções de tempo e frequiência.
O padrão de expansão comumente utilizado é a chamada expansão diádica onde $a_{0}=2$ e $j=1,2,3, \ldots$ Este escalonamento resulta em uma resolução de freqüência logarítmica, diferentemente da STFT onde esta resolução é uniforme.

Para exemplificar a diferença da TWD com a STFT, a Figura 14 apresenta o resultado da análise wavelet do mesmo sinal da Figura 10 usando-se a expansão diádica. Nota-se que o transitório de alta freqüência do sinal pode ser localizado no tempo com uma resolução maior, enquanto que a componente de $60 \mathrm{~Hz}$ aparece com uma magnitude contínua ao longo do tempo.

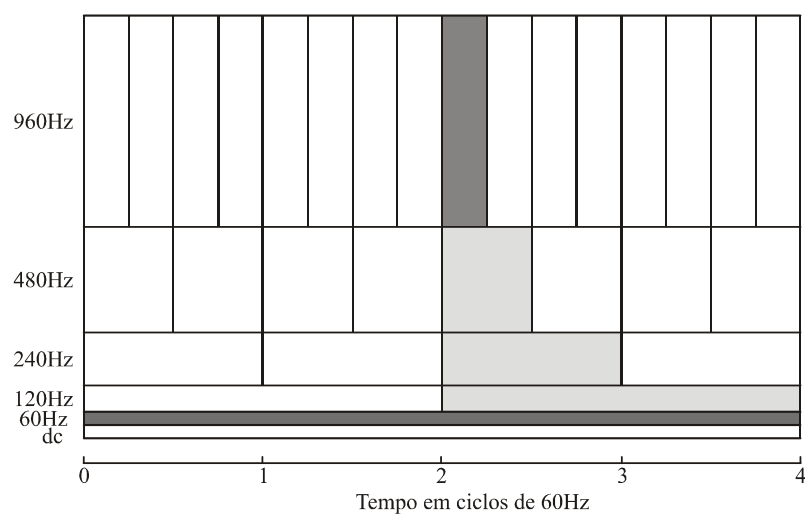

Figura 14: Resultado da análise do sinal da Figura 10 através da transformada wavelet discreta (Robertson et alii, 1996).

O problema do número infinito de funções wavelets necessárias é resolvido através da utilização em conjunto da função de escala $\phi_{a, b}(t)$ que diferentemente $\psi_{a, b}(t)$ possui um espectro do tipo passa-baixas (Chen e Zhu, 2007). Utilizando a função de escala, a TWD pode ser vista como um banco de filtros pelo qual o sinal sob análise é submetido. Esta abordagem, também chamada de análise multirresolução (AMR), resolve o problema da não existência de soluções analíticas para algumas wavelets através da implementação da TW como filtros digitais (Valens, 1999).

Na AMR, utilizando a expansão diádica, a TW pode ser vista como a decomposição do sinal $x[n]$ em diferentes níveis, onde em cada nível o sinal é decomposto em uma versão detalhada e uma atenuada através dos filtros passa-altas e passabaixas, respectivamente. O filtro passa-altas é obtido da função wavelet, enquanto que o passa-baixas provém da função de escala (Oleskovicz et alii, 2006). A Figura 15 apresenta este processo onde o operador downsampling decima o sinal por um fator 2 (o valor de $a_{0}$ neste caso) para o próximo estágio. Uma das vantagens da AMR é sua eficiência computacional (Mix e Olejniczak, 2003).

As características da TWD fazem dela uma ferramenta adequada para a detecção e segmentação de dados de oscilogra- 


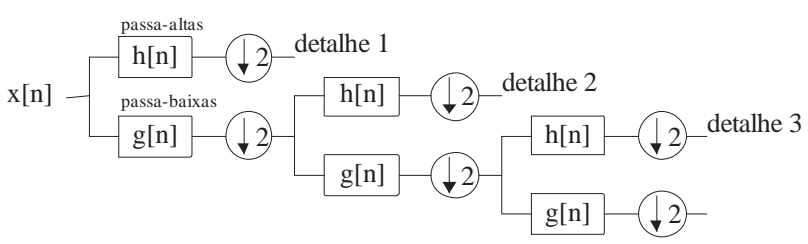

Figura 15: Implementação da TW com a técnica de análise Multirresolução.

fia, tanto para análise de faltas quanto para estudos de qualidade de energia. De fato, o uso da TWD nestes casos tem se tornando freqüente nos trabalhos publicados, principalmente em detecção e classificação de faltas (Youssef, 2001; Silva et alii, 2005; Silva et alii, 2006) e em análise automática de qualidade de energia (Siu e Ngan, 2004; Gaing, 2004).

\section{ALGORITMOS DE TOMADA DE DECI- SÃO}

Diversas técnicas computacionais de tomada de decisão podem ser utilizadas em análise de oscilografias. A maioria dos trabalhos relacionados, inclusive em aplicações reais, utiliza técnicas de inteligência artificial (IA). Estas técnicas são particularmente interessantes, pois visam reproduzir, em programas computacionais, o comportamento de processos da natureza, em especial, a forma como o ser humano aprende e resolve problemas. As técnicas de IA mais conhecidas são as redes neurais artificiais (RNA), os sistemas especialistas, a lógica difusa e os algoritmos genéticos (Rodrigues et alii, 1997). Estas técnicas são bastante utilizadas em sistemas de potência, especialmente as RNAs e os sistemas especialistas, para aplicações em diagnóstico de faltas em equipamentos (Kezunovic, 2004). Na sua utilização em análise de perturbações, além de registros oscilográficos dos RDPs, estas técnicas podem fazer uso de outras fontes de informação, como seqüências de eventos do sistema supervisório e dos relés digitais de proteção. A seguir, os sistemas especialistas e as redes neurais artificiais serão descritos com maior nível de detalhamento.

\subsection{Sistemas Especialistas}

Os sistemas especialistas (SE) são sistemas nos quais buscase incorporar o conhecimento de um ser humano, especialista em determinado assunto, em um programa computacional. Diferentemente de um programa procedimental tradicional, nos sistemas especialistas o conhecimento é separado do mecanismo de raciocínio. De uma forma geral, um SE pode ser esquematizado como na Figura 16.

O conhecimento é armazenado na base de conhecimento, sob duas formas principais: Fatos sobre o problema e regras que

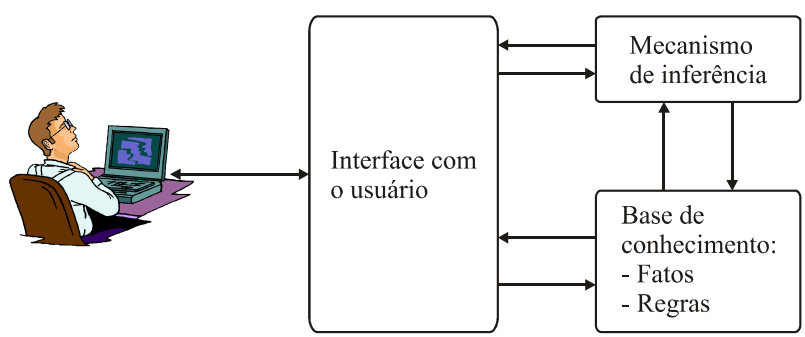

Figura 16: Estrutura básica de um sistema especialista (Mendes, 1997).

indicam como o especialista humano raciocina para chegar a uma conclusão. As regras são do tipo SE premissa(s), ENTÃO conclusão. As premissas são os fatos observados a partir dos dados, como, por exemplo, o valor médio da tensão pré-falta e pós-falta.

A partir dos fatos, o mecanismo de inferência avalia as regras da base de conhecimento, as quais quando disparadas geram novos fatos, até que nenhuma regra possa ser executada com os fatos atuais ou que uma meta já tenha sido alcançada.

Através da interface, o usuário pode inserir novas regras e fatos, além de poder acompanhar todo o processo de tomada de decisão (regras executadas e fatos utilizados) realizado pelo sistema especialista. É também através da interface que o usuário recebe a resposta final da análise.

Em suas aplicações à análise de oscilografias, os sistemas especialistas normalmente são utilizados em conjunto com técnicas de processamento digital de sinais. As características extraídas dos dados constituem os fatos da base de conhecimento que são confrontados com as regras pelo mecanismo de inferência. Como exemplo, considere a seguinte regra: SE a tensão e a corrente pós-falta são nulas ENTÃO provavelmente ouve um desligamento. Assim através do encadeamento de diversas regras deste tipo, o SE pode chegar a uma conclusão a respeito da ocorrência (Moreto e Rolim, 2007).

Um dos aspectos positivos dos sistemas especialistas é que o processo de tomada de decisão pode ser visualizado pelo usuário, o qual pode ao longo do uso do sistema propor melhorias na base de conhecimento. A separação do mecanismo de inferência da base de conhecimento permite que esta última possa ser atualizada constantemente. No entanto, para que os SEs possam ser utilizados, são necessárias informações detalhadas a respeito do problema e como ele é solucionado por especialistas humanos. Deve-se também tomar muito cuidado na representação deste conhecimento, de tal forma que o SE possa obter uma saída a partir dos fatos obtidos no sistema real.

Os SEs têm sido amplamente utilizados na análise de osci- 
lografia para a solução de diversos problemas como: análise de faltas (Kezunovic, 2000) e (Luo e Kezunovic, 2005b); análise de operação de disjuntores (Kezunovic et alii, 2005), análise de qualidade de energia (Styvaktakis et alii, 2002a) e análise da proteção (Luo e Kezunovic, 2005a).

\subsection{Redes Neurais}

As Redes Neurais Artificiais (RNAs) foram desenvolvidas tomando-se como base o neurônio, unidade funcional do cérebro humano. Na sua concepção mais usual, chamada de Perceptron de Múltiplas Camadas (Multilayer Perceptron MLP), as RNAs fazem uma representação distribuída da informação, na forma de conexões entre um grande número de elementos simples (neurônios artificiais). Todos esses elementos realizam operacionalmente a mesma função, ou seja, a soma ponderada de suas entradas seguida de uma transformação (linear ou não-linear) sobre este valor. Assim, as Redes Neurais Artificiais são modelos matemáticos simplificados dos neurônios biológicos e suas interconexões em redes.

A Figura 17 apresenta o modelo matemático tradicional de um neurônio artificial utilizado nas redes MLP.

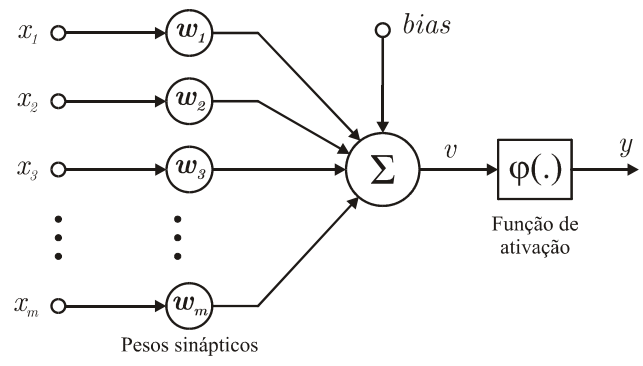

Figura 17: RNA, modelo matemático de um neurônio artificial.

A informação sobre a solução do problema é armazenada nos pesos sinápticos $\omega_{m}$ os quais são obtidos a partir de um processo de aprendizagem através de exemplos conhecidos aplicados à RNA (Haykin, 2001).

A grande vantagem no uso de redes neurais artificiais para solução de problemas complexos provém principalmente de sua capacidade de aprendizagem através de exemplos e generalização da resposta. Com isso, as RNA são utilizadas em problemas onde uma solução analítica ou numérica não pode ser obtida.

Na análise de oscilografias, as características obtidas através de técnicas de processamento de sinais são aplicadas às entradas da RNA do tipo MLP. Primeiramente é realizado um processo de treinamento da rede, utilizando um conjunto de entradas/saídas conhecidas. Através de um processo de oti- mização os pesos sinápticos são estimados de modo que o erro da saída obtida em relação a desejada seja minimizado. Após um processo de treinamento adequado a RNA passa a generalizar a saída para casos não utilizados no treinamento, assim, ela está pronta para ser utilizada na aplicação. Conforme a estrutura da rede, um conjunto de saídas pode ser obtido, representando o tipo de ocorrência identificada na oscilografia.

Diversos exemplos de aplicação de RNA na análise de oscilografias podem ser encontrados na literatura. Em Silva et alii (2006) e Silva et alii (2007) a RNA é utilizada para classificar faltas em sistemas de transmissão, tendo como entrada amostras dos sinais de corrente e tensão. Em em Oleskovicz et alii (2003) um conjunto de RNAs é utilizado para detectar, classificar e localizar faltas em linhas transmissão também utilizando amostras dos sinais. Em Ferreira et alii (2009), a RNA é utilizada para classificação de eventos de qualidade de energia, tendo como entradas parâmetros estatísticos calculados a partir do sinal amostrado. No trabalho de Bretas et alii, (2006), utiliza-se a RNA para localização de faltas em linhas de distribuição a partir das componentes harmônicas originadas em faltas de alta impedância.

Alguns aspectos devem ser levados em conta antes de se optar pelo uso das RNAs. Em primeiro lugar, para que a RNA funcione adequadamente, faz-se necessário um conjunto de dados para treinamento, o que muitas vezes não está disponível. Estes dados, no entanto, podem ser obtidos através de simulações computacionais, mas deve-se ficar atento à modelagem adequada do problema, quando esta é viável. Em segundo lugar, nas RNAs tradicionais (como a MLP), diversas heurísticas estão envolvidas na escolha da topologia da rede, nos seus parâmetros e na forma de treinamento. Escolhas inadequadas podem ocasionar deficiências na generalização do resultado para casos não previstos no treinamento, ou seja, a RNA pode decorar os resultados do treinamento e com isso apresentar erros elevados quando aplicada em situações reais. Em terceiro lugar, convém ressaltar que a RNA não apresenta ao usuário o raciocínio lógico utilizado para a obtenção do resultado, caso este se faça necessário na aplicação proposta.

\section{CONSIDERAÇÕES FINAIS}

Foi apresentada uma visão geral das aplicações dos registros de oscilografia em instalações de sistemas de energia elétrica, tanto em âmbito nacional quanto mundial. Verificou-se que a oscilografia é umas das fontes de dados mais utilizadas para diagnóstico de sistemas de energia. Suas aplicações podem ser em diagnóstico de faltas (detecção e localização), análise do desempenho de equipamentos, como disjuntores, estudos de qualidade de energia e avaliação do desempenho dos sistemas de proteção. O uso da oscilografia pode ser combinado 
com outras fontes de dados, como sequências de eventos de sistemas supervisórios e internas aos relés digitais de proteção.

Um grande esforço vem sendo realizado pela comunidade acadêmica no sentido de desenvolver ferramentas que realizem análises automáticas de oscilografias, pois com as redes de oscilografia cada vez mais presentes, a quantidade de dados a ser analisada tem prejudicado a qualidade dos diagnósticos obtidos pelos engenheiros analistas. A maioria dos trabalhos visa realizar uma espécie de filtragem nos dados de oscilografia, possibilitando que os profissionais responsáveis foquem sua atenção nos casos mais importantes, como desligamentos forçados, por exemplo. Até mesmo para estes casos estão sendo propostos métodos de análise automática, identificando, por exemplo, o tipo da falta e se esta foi interna ou externa à instalação onde está localizado o RDP.

Os métodos de análise automática de ocorrências em sistemas de potência, na maioria dos casos, são combinações de técnicas de processamento de sinais, destacando-se a Transformada Wavelet, com algoritmos de inteligência computacional. Dentre estes, os mais utilizados são sistemas especialistas e as redes neurais artificiais.

Um breve resumo destas técnicas foi apresentado na expectativa de que possa servir como base para o desenvolvimento de novas aplicações neste assunto ou para o aprimoramento de metodologias existentes.

\section{REFERÊNCIAS}

Bretas, A. S., Moreto, M., Salim, R. H., Pires, L. (2006). A Novel High Impedance Fault Location for Distribution Systems Considering Distributed Generation. Proceedings of IEEE PES Transmission and Distribution Conference and Exposition Latin America. Caracas, Venezuela, pp. $1-6$.

Bollen, M. H. J. and Gu, I. Y. H. (2006). Signal Processing of Power Quality Disturbances. IEEE Press, USA.

Chen, S. and Zhu, H. Y. (2007). Wavelet Transform for Processing Power Quality Disturbances. EURASIP Journal on Advances in Signal Processing, Vol. 2007, pp. 1 19.

Davidson, E. M., McArthur, S. D. J. and McDonald J. R. (2003). A Toolset for Applying Model-Based Reasoning Techniques to Diagnostics for Power Systems Protection. IEEE Transactions on Power Systems, Vol. 18, $\mathrm{n}^{\circ} 2$, pp. $680-687$.

Davidson, E. M., McArthur, S. D. J., McDonald J. R.; Cumming, T. and Watt, I. (2006). Applying multi-agent system technology in practice: automated management and analysis of SCADA and digital fault recorder data. IEEE Transactions on Power Systems, Vol. 21, $\mathrm{n}^{\circ}, 2$; pp. $559-567$.

Ferreira, D. D., Cerqueira, A. S., Marques, C. A. G., Duque, C. A., Ribeiro, M. V. (2009). Sistema Automático de Detecção e Classificação de Distúrbios Elétricos em Qualidade de Energia Elétrica. Revista Controle \& Automação. Vol. 20, $\mathrm{n}^{\circ} 1$, pp. $53-62$.

Futino E., Pereira, G., Bittencourt, A. A., Lachman, M. e Rolim, J. G. (2009). Desenvolvimento de um Sistema de Monitoração Remota e Avaliação do Estado Operativo de Transformadores de Potencial Capacitivos (TPCs). Anais XI Simpósio de Especialistas em Planejamento da Operação e Expansão Elétrica. Belém PA, pp. 1 6.

Gaing, Z.-L. (2004). Wavelet-Based Neural Network for Power Disturbance Recognition and Classification. IEEE Transactions on Power Delivery, Vol. 19, No. 4; pp. $1560-1568$.

Giovanini R., Rodrigues, M. A. M., Moraes, R. M., Oliveira, J. C. C., Gonçalves, D. N., Miranda, A. L. L., Diniz, S. S. e Figueiredo, M. V. F. (2008). SPERT - Sistema Integrado para Análise de Perturbações. Anais do IX Seminário Técnico de Proteção e Controle - STPC. Belo Horizonte, MG.

Girgis, A. A. and Fallon, C. M. (1992). Fault location techniques for radial and loop transmission systems using digital fault recorded data. IEEE Transactions on Power Delivery. Vol. 7, n ${ }^{o}$ 4, pp. 1936 - 1945.

Haykin, S. (2001). Redes Neurais: Princípios e Prática. $2^{a}$ edição. Porto Alegre, Bookman.

Hossack, J., McArthur, S. D. J., McDonald, J. R., Stoke, J. and Cumming, T. (2002). A multi-agent approach to power system disturbance diagnosis. Proceedings of Fifth International Power System Management and Control, pp. $317-322$.

Kezunovic, M. and Perunicic, B. (1995). Synchronized sampling improves fault location. IEEE Computer Applications in Power, Vol. 8, No. 2; pp. 30 - 33.

Kezunovic, M. (2000). Practical Applications of Automated Fault Analysis. Proceedings of International Conference on Power System Technology. Vol. 2; pp. 819 824.

Kezunovic, M., Liu, C. C., McDonald, J. and Smith, L. E. (2001). Automated Fault Analysis, IEEE Tutorial, IEEE PES. 
Kezunovic, M. (2004). Intelligent applications in substations: Disturbance analysis. Proceedings of IEEE Power Engineering Society General Meeting. Vol. 1, Denver, USA, pp. 719-723.

Kezunovic, M., R. Zhifang, Latisko, G., Sevcik, D.R., Lucey, J.S., Cook, W.E. and Koch, E.A. (2005). Automated monitoring and analysis of circuit breaker operation. IEEE Transactions on Power Delivery, Vol. 20, No. 3; pp. $1910-1918$.

Liu, C.-W., Lien, K.-P., Chen, C.-S. and Jiang, J.-A. (2008). A Universal Fault Location Technique for N-Terminal $(\mathrm{N} \geq 3)$ Transmission Lines. IEEE Transactions on Power Delivery, Vol. 23, No. 3; pp. 1366 - 1373.

Luo, X. and Kezunovic, M. (2005a). Automated Analysis of Digital Relay Data Based on Expert System. Proceedings of Power Tech 2005 Conference, St. Petersburg, RU.

Luo, X. and Kezunovic, M. (2005b). Fault analysis based on integration of digital relay and dfr data. Proceedings of 2005 IEEE Power Engineering Society General Meeting, Vol. 1, pp. $746-751$.

Martínez, J. K., et alii. (2008). Fault and Disturbance Data Analysis Including Intelligent Systems. Report 355, Working Group B5.03, CIGRE.

McArthur, S. D. J., Davidson, E. M., Hossack, J. A. and McDonald, J. R. (2004). Automating power system fault diagnosis through multi-agent system technology. Proceedings of the 37th Annual Hawaii International Conference on System Sciences, pp. 1 - 6.

Melo, M. O. B. C. (2008). Avaliação do impacto da qualidade de energia elétrica na produção industrial: proposta de metodologia. Produto \& Produção, vol. 9, n ${ }^{o} 3$, pp. 15 -25 .

Mendes, R. D. (1997). Inteligência Artificial: Sistemas Especialistas no Gerenciamento da Informação. Ciência da Informação. Brasília; Vol. 26; No. 1; pp. 39 - 45.

Mix, D. F., Olejniczak, K. J. (2003). Elements of Wavelets for Engineers and Scientists. John Wiley \& Sons, Inc., Hoboken, New Jersey, USA.

Moreto, M. e Rolim, J. G. (2007). Sistema Especialista Para Pré-análise de Oscilografias Voltado Para Geração. Anais do VIII Simpósio Brasileiro de Automação Inteligente, Florianópolis, pp. 1 - 6.

Moreto, M. and Rolim, J. G. (2008). Automated Analysis of Digital Fault Recorder Data in Power Generating Plants. Proceedings of $16^{\text {th }}$ Power Systems Computation Conference - PSCC, Glasgow, UK, pp $1-6$.
Oleskovicz, M., Coury, D. V. e Aggarwal, R. K. (2003). O Emprego de Redes Neurais Artificiais na Detecção, Classificação e Localização de Faltas em Linhas de Transmissão. Revista Controle \& Automação. Vol. 14, $\mathrm{n}^{o} 2$, pp. $138-150$.

Oleskovicz, M., Coury, D. V., Carneiro, A. A. F. M., Arruda, E. F., Delmont, O., Souza, S. A. (2006). Estudo Comparativo de Ferramentas Modernas de Análise Aplicadas à Qualidade de Energia Elétrica. Revista Controle \& Automação. Vol. 17, $\mathrm{n}^{\circ}$ 3, pp. $331-341$.

ONS (2002). Requisitos Mínimos dos Sistemas de Proteção, Supervisão/Controle e de Telecomunicações. Procedimentos de rede, submódulo 2.5. [S.1.]:ONS, Dez. 2002. Disponível em: <http://www.ons.org.br>.

Phadke, A. G. and Thorp, J. S. (1988). Computer Realaying for Power Systems, Research Studies Press, Baldock, Hertfordshire, England.

Phillips, C.L; Parr, J.M. (1995) Signals, systems and Transforms. Prentice Hall.

Robertson, D. C., Camps, O. I., Mayer, J. S., Gish, W. B. (1996).Wavelets and Electromagnetic Power System Transients. IEEE Transactions on Power Delivery. Vol. $11, \mathrm{n}^{\circ} 2$, pp. $1050-1058$.

Rodrigues, M. A. M., Filho, S. M. e Vilela, J. M. de F. (1997). Ferramentas computacionais tradicionais e inteligentes para análise de perturbações em sistemas de potência. Anais do XIV Seminário Nacional de Produção e Transmissão de Energia Elétrica (SNPTEE), Belém, pp. 1 6.

Sachdev, M. S. and Baribeau, M. A. (1979). A New Algorithm for Digital Impedance Relays. IEEE Transactions on Power Apparatus and Systems, vol. PAS-98, $\mathrm{n}^{\circ}$ 6 , pp. $2232-2240$.

Silva, K. M., Souza, B. A., Brito, N. S. D. (2006). Fault Detection and Classification in Transmission Lines Based on Wavelet Transform and ANN. IEEE Transactions on Power Delivery, Vol. 21, no 4, pp. 2058 - 2063.

Silva, K. M., Souza, B. A., Brito, N. S. D., Dantas, K. M. C., Costa, F. B. e Silva, S. S. B. (2007). Detecção e Classificação de Faltas a Partir da Análise de Registros Oscilográficos via Redes Neurais Artificiais e Transformada Wavelet. Revista Controle \& Automação, Vol. 18, $\mathrm{n}^{o} 2$, pp. $163-172$.

Silva, M. da, Oleskovicz, M. e Coury, D. V. (2005). Uma Nova Ferramenta Baseada na Transformada Wavelet para Localização Digital de Faltas. Revista Controle \& Automação. Vol. 13, n ${ }^{o}$ 3, pp. 345 - 358 . 
Silva, M. S., Jardini, J. A., Magrini, L. C., Corvo, A., Solis, L. A. and Veiga, F. (2004). Determination of the Circuit Breaker Operation Times Using the Wavelet Transform. Proceedings of Power Engineering Society General Meeting 2004, Denver USA, Vol. 2, pp. 1214 1219.

Siu, H. K. and Ngan, H. W. (2004). Automatic power quality recognition system using wavelet analysis. Proceedings of the 2004 IEEE International Conference on Electric Utility Deregulation, Restructuring and Power Technologies. Vol. 1; pp. $311-316$.

Styvaktakis, E., Bollen, M. H. J. and Gu, I. Y. H. (2002a). Expert System for Classification and Analysis of Power System Events. IEEE Transactions on Power Delivery, Vol. 17, n ${ }^{\circ} 2$, pp. $423-428$.

Styvaktakis, E., Bollen, M. H. J. and Gu, I. Y. H. (2002b). Automatic Classification of Power System Events Using rms Voltage Measurements. Proceedings of Power Engineering Society Summer Meeting, Vol. 2, pp. $824-829$.

Tcheou, M. P. (2005). Análise e Representação de Sinais de Oscilografia Usando Decomposiçõess Adaptativas Redundantes. Tese (Doutorado em Engenharia Elétrica). Universidade Federal do Rio de Janeiro, Rio de Janeiro, 2005.

Vale, D. T., Coser, J. e Rolim, J. G. (2006). F-LOC - Ferramenta Inteligente para Diagnóstico de Faltas em Sistemas de Distribuição de Energia. Anais do XVI Congresso Brasileiro de Automática, Salvador, BA, pp. 1 6.

Valens, C. (1999). A Really Friendly Guide to Wavelets. Acessível em http://pagesperso-orange. fr/polyvalens/cle-mens/clemens.html.

Varela, F. S., Rolim, J. G., Moreto, M., Lenz, E. P., Kato, L. H. e Zimath, S. L. (2009). iOSC - Sistema Iinteligente de Gestão de Oscilografias. Anais do XX Seminário Nacional de Produção e Transmissão de Energia Elétrica - SNPTEE, Recife, PE, pp. $1-6$.

Xu, J., Senroy, N., Suryanarayanan, S., Ribeiro, P. (2006). Some Techniques for the Analysis and Visualization of Time-varying Waveform Distortions. Proceedings of 38th North American Power Symposium, pp. 257 - 261.

Youssef, O. A. S. (2001). Fault classification based on wavelet transforms. Proceedings of 2001 IEEE/PES Transmission and Distribution Conference and Exposition. Vol. 1; pp. $531-536$.
Zimath, S. L; Neves, F. C.; Espíndola, T. S. (2005). Monitoração de Eventos com Registro de Longa Duração - Configuração e Aplicação. Anais do VIII Seminário Técnico de Proteção e Controle, Rio de Janeiro RJ.

Zin, A. A. M. and Karim, S. P. A. (2007). The Utilization of Digital Fault Recorders in Protection System Analysis on Tenaga Nasional Berhad Transmission System. IEEE Transactions on Power Delivery, Vol. 22, $\mathrm{n}^{\circ} 4$, pp. $2040-2046$. 